\title{
Letter to the Editor: Why Are Korean Baby Boomers More Depressed Than the Older Generation?
}

I recently read Jang's study ${ }^{1)}$ published on the Annals of Geriatric Medicine and Research with great interest. I believe that it asks a meaningful question regarding whether baby boomers, a population group that has experienced drastic events of the modern history of Korea in the last 50 years, are healthy or not. The author compared baby boomers born between 1955 and 1963 with those who were born before 1955. Jang ${ }^{1)}$ concluded the following: "There is a conflicting story about the state of health of the baby boomers. Some results showed a prevalence of depression symptoms that was greater than the older generation and a good response to health in terms of self-rated health, health behaviors, healthcare utilization, and suicidal ideation."

I would like to point out 2 issues with Jang's results"). The first issue is whether the methodology used by Jang was appropriate or not. The author used a generalized estimating equation model to compare the average health status of baby boomers and that of the previous generation. The effects of major demographic variables were controlled by adding sex, educational status, occupational status, marital status, household income, and beneficiaries of basic living aids into this model. However, what about age? The mean age of the study subjects of the baby boomer generation and the previous generation was $48.9 \pm 2.6$ years, and $65.6 \pm 8.1$ years, respectively. This means that the author was comparing the health status between 2 groups that had an age gap of almost 20 years. Therefore, the difference in the health status observed between the 2 groups must have been a result of a combination of age and cohort effects. With the method used by Jang, the question, "are baby boomers healthier than the previous generation?" cannot be answered.

One way to solve this problem is to adopt the matching method by using not all the samples but only partial samples to make a control group with high comparability. For instance, a sample taken in 2014 of people born in 1955 (experimental group) and a sample taken in 2008 of people born in 1949 (control group) can be compared. This way, the subjects in both the groups are 59 years old at the time of comparison, and the cohort effects can be compared without being affected by age effect. The time window can be extended to compare, for instance, a 2014 sample of people born between 1955 and 1960, and a 2008 sample of people born between 1949 and 1954. If we use the propensity score match- ing method, samples with matching age and other major health-related factors may also be created. Of course, this method requires the assumption that there are no impact on the period effects between the 2 time points such as a financial crisis.

Despite this limitation in Jang ${ }^{1)}$ 's methodology, I do believe that Jang's conclusion is not wrong. Especially, I believe that the finding which the baby boomer generation has higher depressive tendencies than the previous generation is very meaningful. Considering that depression is influenced by lifetime cumulative adversity as reported in the previous literatures ${ }^{2,3)}$, the higher depressive tendencies in the baby boomer generation than in the previous one cannot be explained by age effects alone. In other words, the higher depressive tendencies of the baby boomer generation should be viewed as a result of cohort effects and seem to be serious to the point where they are beyond the effects of 20 -year lifetime adversity (age effects). Why are baby boomers more depressed than the previous generation? This is the second issue which I raise.

While it would not be possible to get a complete answer to this question through the present research, I believe that it is necessary to trace the life histories of the baby boomers and look closely at the psychosocial events experienced by this population group in further investigation. This is because biological factors (e.g., neurobiological changes caused by genetic factors, cognitive diathesis) alone cannot adequately explain the differences in the incidence rate of depression between cohorts ${ }^{4}$. During the period between 1960 and 2010 - when baby boomers had lived - Korea underwent drastic demographic changes that were unprecedented in the world history. These include changes in the age population structure, transformation of the economic structure from an agricultural society to industrial society, overpopulation in the urban areas around Seoul and the capital area, changes in the number of persons per household, and changes in people's perspective on family in response to an increase in the average lifespan of the nation. As a result of these changes, the environmental aspects around us, including clothes, food, and housing have all changed at the microscopic level. While Korea is more economically prosperous now without absolute poverty compared to the past, the sudden sociocultural changes may have been embedded in 
the brains of the baby boomers as something negative. In this respect, I believe it is necessary that follow-up researchers deeply think about why the baby boomer generation is more depressed than the previous generation by looking at cumulative lifetime adversity of both groups - especially because the baby boomers are now knocking on the door to their senescence.

Conflicts of Interest Disclosures: The researcher claims no conflicts of interest.

\section{Chang-O Kim}

Institute of Social Welfare, SungKongHoe University, Seoul, Korea

Corresponding Author: Chang-O Kim, MD

Institute for Social Welfare, SungKongHoe University,

320 Yeondong-ro, Guro-gu, Seoul 08359, Korea

Tel: +82-70-4665-9492, Fax: +82-2-875-9209

E-mail: nation@snu.ac.kr

Received: May 17, 2017

Revised: May 18, 2017

Accepted: June 2, 2017

\section{REFERENCES}

1. Jang SN. Trends of health status and medical utilization among Korean baby boomers: Analysis from Korean Health Panel Survey 2008-2014. Ann Geriatr Med Res 2017;21:24-30.

2. Dannefer D. Cumulative advantage/disadvantage and the life course: Cross-fertilizing age and social science theory. J Gerontol B Psychol Sci Soc Sci 2003;58:S327-37.

3. Shrira A. The effect of lifetime cumulative adversity on change and chronicity in depressive symptoms and quality of life in older adults. Int Psychogeriatr 2012;24:1988-97.

4. Fiske A, Wetherell JL, Gatz M. Depression in older adults. Ann Rev Clin Psychol 2009;5:363-89. 